\title{
Analysis of fibres in human lung tissue
}

\author{
B GYLSETH, R H BAUNAN, AND L OVERAAE
}

From the Institute of Occupational Health, Oslo, Norway

ABSTRACT Standard UICC crocidolite fibres and fibres extracted from occupationally exposed human lung tissue have been analysed by scanning electron microscopy after different preparation procedures. A significant fibre loss has been shown due to the adhesion of fibres to the beakers. Fibres are also discarded during the washing and extraction of the lung tissue samples. The recovery was found to be 30 to $40 \%$ both for UICC standard specimens and for lung tissue samples.

Fibres in occupationally exposed and non-exposed human lungs are extracted from the tissue samples in different ways before they are evaluated by number and size. The extraction techniques include wetdigestion (WD) in potassium hydroxide, ${ }^{12}$ sodium hypochlorite $^{3}{ }^{4}$ and formamide, ${ }^{5}$ dry-ashing by low-temperature plasma incineration, ${ }^{6-8}$ and high temperature ashing. After extraction, the fibres may be evaluated by optical microscopy, ${ }^{24}$ scanning electron microscopy 6 or transmission electron microscopy, ${ }^{13}$ or combinations of all three methods. ${ }^{6} 8$

Due to several factors, results obtained in different studies cannot be directly compared. Sebastien et $a l^{3}$ and Gylseth and Baunan ${ }^{9}$ have shown that fibres and asbestos bodies are unevenly distributed in the human lung. Therefore, the tissue specimens should be sampled at standard sites. Ashcroft and Heppleston $^{2}$ and Gylseth et $a l^{6}$ have shown that fibres break during the drying of the tissue samples because of shrinkage, thereby altering both the number and the size distribution. The different extraction techniques include washing, centrifugation, and decantation using either ether ${ }^{4}$ or distilled water, ${ }^{3}$ which may induce loss of fibres. Weill, ${ }^{10}$ summing up at the Biological Effects of Mineral Fibres' Congress in Lyon, 1980, stated that the extraction techniques may be checked by relating the known amount of added fibre and the result of the quantitative analyses. So far as we know such data have not been published. From an analytical point of view, the magnitude of the errors introduced both during the preparation procedures and in the analysis should be determined or at least

Requests for reprints to: Mr B Gylseth, Institute of Occupational Health, PO Box 8149 Dep, Oslo 1, Norway.

Received 3 July 1981

Accepted 11 August 1981 estimated. The purpose of the present study was to investigate how fibres are lost and to determine the magnitude of the loss by employing different preparation procedures.

\section{Materials and methods}

One to two milligrams of standard UICC crocidolite was suspended in $100 \mathrm{ml}$ of distilled water. A few millilitres of ethanol were added to the suspension to reduce the surface tension, thus avoiding hydrophobic areas on the filters during filtration. After homogenisation of the suspension in an ultrasonic bath for five minutes, a 1/25 dilution was made. After a new homogenisation, 5-ml aliquots of this suspension were pipetted into $15-\mathrm{ml}$ centrifuge tubes and one of the following procedures used:

(1) Direct filtration of suspensions.

(2) Addition of $5 \mathrm{ml}$ sodiumhypochlorite, centrifugation for $4000 \mathrm{rpm}$ for 20 minutes, pipetting off the supernatant, adding 5-ml distilled water, and resuspending the fibres. The procedure was repeated twice.

(3) Same as (2), but now $20000 \mathrm{rpm}$ for 20 minutes were used.

(4) Same as (2), but $250-350 \mathrm{mg}$ of wet tissue was added to the hypochlorite suspension. The tissue was taken from the lungs of an unexposed person and contained very few fibres.

(5) Suspensions of crocidolite $(0.4$ mill fibres $/ \mathrm{ml})$ were stored in glass and plastic beakers for $0,4,24,48$, and 72 hours before filtration and analysis. Each vial was sonicated for five minutes before filtration.

Two sets of suspensions, to which were added $4 \%$ formaline and $0.05 \%$ hyamine respectively, were stored for $\mathbf{4 8}$ hours.

Four parallel samples were run in each group except for the stored samples, where only two parallel samples were analysed. All samples were 
filtered on $0 \cdot 2-\mu \mathrm{m}$ pore size, $47-\mathrm{mm}$ diameter Nuclepore membranes.

In another series of experiments, adjacent lung tissue samples from exposed individuals were analysed for fibres.

(6) Wet-digestion of $250-350 \mathrm{mg}$ of formaldehydefixed lung tissue in 5-ml $1 \mathrm{~N}$ sodiumhypochlorite in $0 \cdot 1 \mathrm{~N}$ sodiumhydroxide. Fat was removed by diethylether extraction.

(7) Low-temperature plasma ashing of $25-35 \mathrm{mg}$ (dry weight) of tissue samples adjacent to those in (6).

The procedures were tested for two series of lung samples: the first comprised adjacent samples taken at six different sites in the lung and the second, six adjacent specimens sampled at the same site in another lung. The wet to dry weight relationship was determined by weighing half of the samples in both the wet and the dry condition.

After filtration, small pieces of the Nuclepore membranes were cut, coated with gold, and the fibres counted in a Jeol Jsm-35 scanning electron microscope following the method described by Gylseth et al. ${ }^{6}$

\section{Results}

The results for the different extraction procedures compared with those from the direct filtration show a recovery ranging from 34 to $40 \%$ (table 1 ).

The data from the tissue analyses are shown in table 2 and fig 1 . On average, low-temperature plasma ashing gave counts $4 \cdot 3$ times higher than wet-digestion for the first set of lung tissue samples,

Table 1 Percentage recovery of fibres after the different preparation procedures have been applied on standard asbestos suspensions

\begin{tabular}{lccc}
\hline Procedure & No of fibres $/ \mathrm{mm}^{2} \pm S D$ & $\%$ recovery \\
\hline 1 & 2660 & 141 & - \\
2 & 914 & 161 & 34 \\
3 & 1059 & 246 & 40 \\
4 & 1013 & 166 & 38 \\
\hline
\end{tabular}

Table 2 Comparison of results from analysis of adjacent tissue samples after low-temperature plasma ashing and wet-digestion respectively

\begin{tabular}{lll}
\hline Sample & \multicolumn{2}{c}{ Million fibres/g dried tissue } \\
\cline { 2 - 3 } & $\begin{array}{l}\text { Low-temperature } \\
\text { plasma ashing }(7)\end{array}$ & $\begin{array}{c}\text { Wet-digestion } \\
(6)\end{array}$ \\
\hline 1 & 287 & 113 \\
2 & 365 & 86 \\
3 & 548 & 104 \\
Mean & 400 & 101 \\
SD $(\%)$ & 34 & 14 \\
MeantTA/meanwD & 4.0 & \\
\hline
\end{tabular}

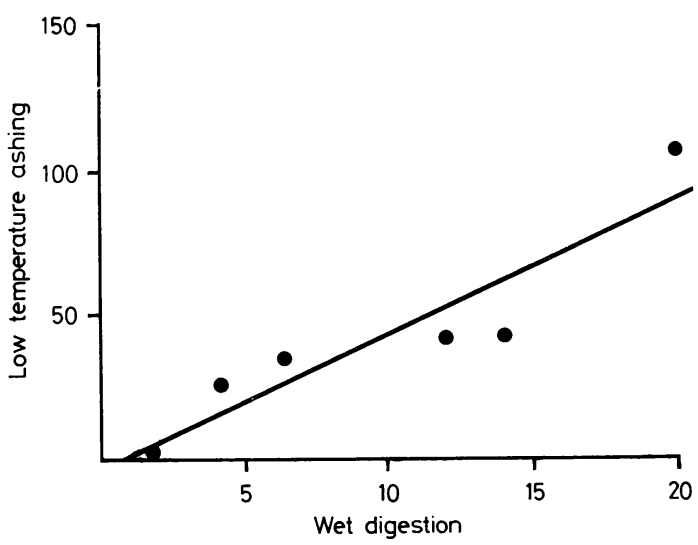

Fig 1 Relation between fibre numbers obtained after low-temperature plasma ashing and wet-digestion for six pairs of adjacent tissue specimens sampled at different sites in one set of human lungs. On both scales: million fibres per gram of dried tissue.

and 4.0 times for the second set of samples. The supernatant from the extraction procedure was analysed for fibres and found to contain on average $12 \%$ of the total number of fibres. As long as only a fraction of the fibres is found in the supernatant, the rest must be found on the glass walls. Analysis of pieces of glass equipment in the scanning electron microscope showed that fibres were attached to the beaker (fig 2). Glassware (beakers, centrifuge glasses) used for the tissue analyses even had large asbestos bodies attached to the walls (fig 3). No attempt was made to quantify the number of the adhered fibres. Sonication and thorough use of a

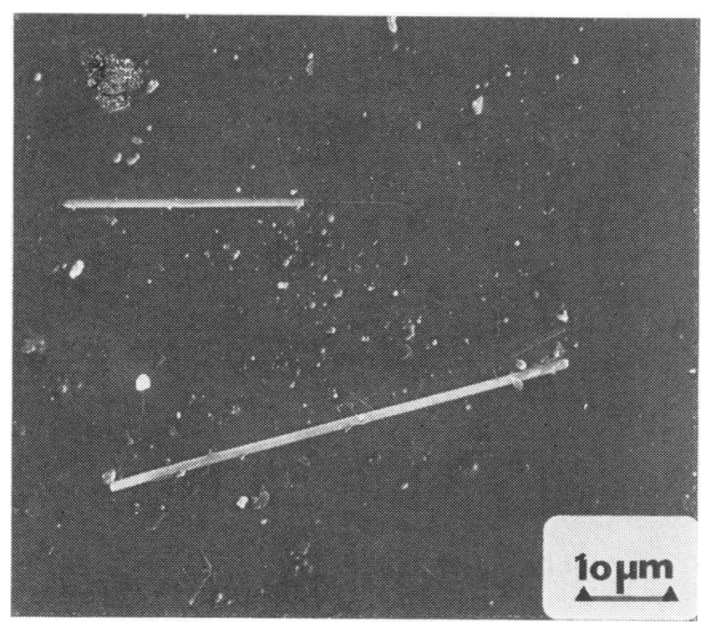

Fig 2 Standard UICC crocidolite fibres attached to glass $(\times 1000)$. 


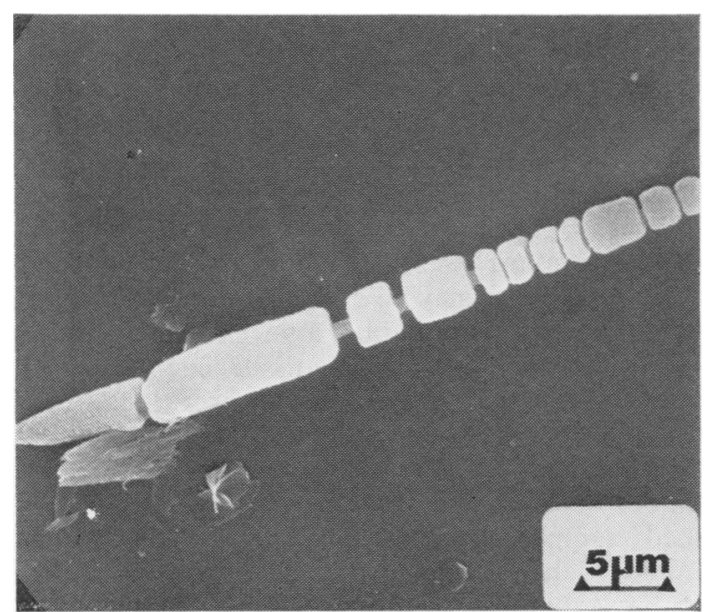

Fig 3 Asbestos body attached to glass $(\times 2000)$.

"rubber policeman" before filtration did improve the recovery slightly.

Figure 4 shows the reduction of the fibre number in standards stored for different periods. The

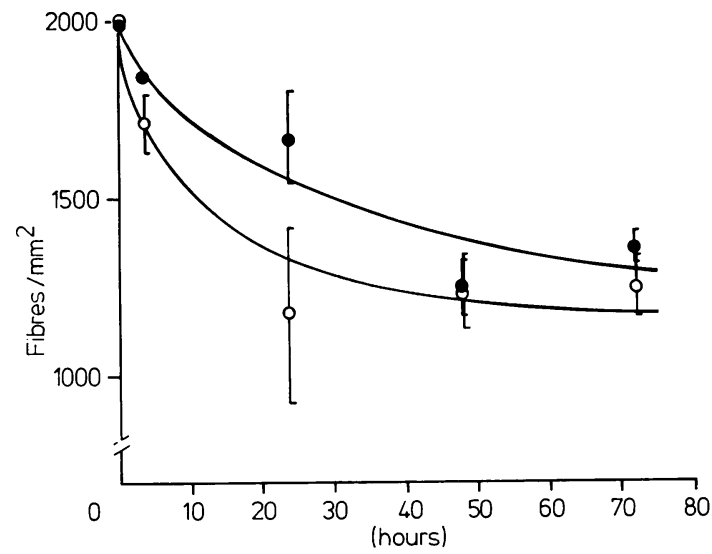

Fig 4 Reduction of fibre number during storage of fibre suspension in glass $(\bigcirc)$ and in plastic beakers $(O)$.

addition of a bactericidal (formaline) or a detergent (Hyamine 2389, from BDH Chemicals Ltd) did not improve the fibre recovery. Siliconisation of the glass beakers and the use of Pt-crucibles were also tried without any improvement.

Micro-organisms grow very well in distilled water/ asbestos suspensions. One milligram of crocidolite per $100 \mathrm{ml}$ of water gives agglomeration and attachment of fibres and micro-organisms to the glass already after storage for one day. This is illustrated in figs 5-8, showing fibres and micro-organisms

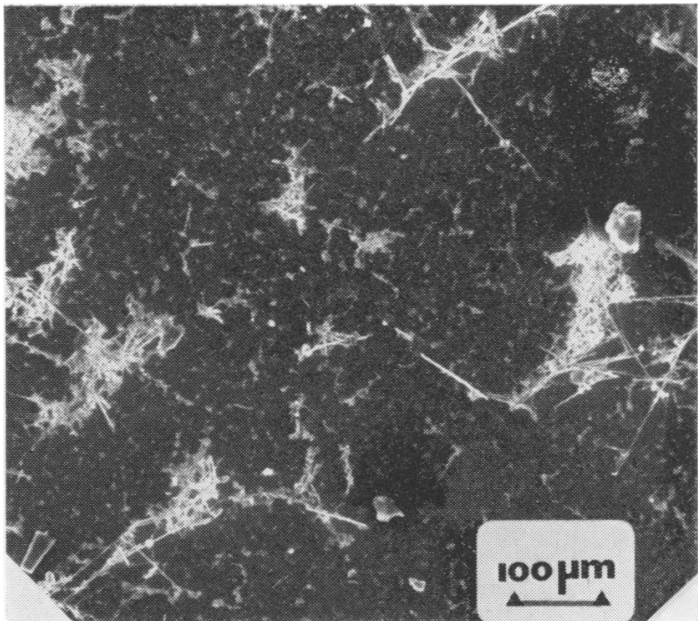

Fig 5 Lumps of fibres and micro-organisms attached to glass photographed in scanning electron microscope $(\times 100)$.

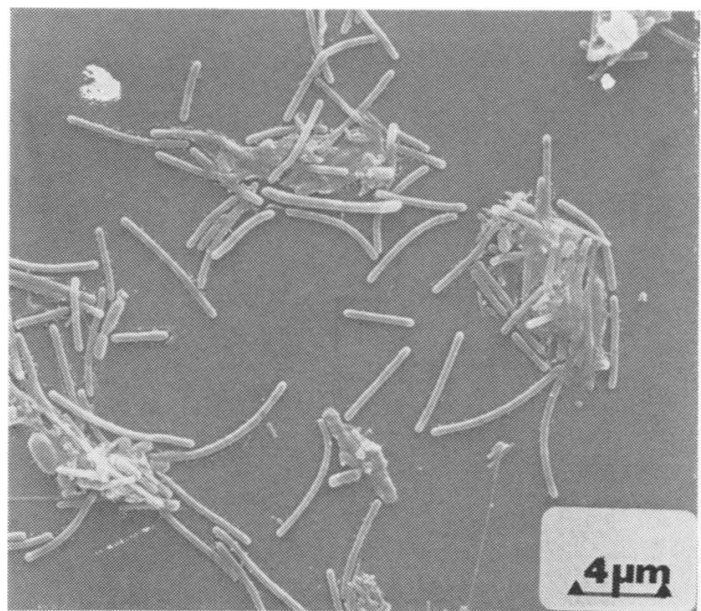

Fig 6 Micro-organisms and fibres photographed at $\times 2400$ magnification.

attached to the glass. The samples were fixed in glutaraldehyde, osmium tetraoxide, dehydrated in graded acetone, and critical point dried before analysis in the scanning electron microscope.

\section{Discussion}

Opinions vary on how fibres in biological tissues should be extracted and analysed. Some of the analytical problems could, however, be overcome by inter-laboratory comparisons, as for airborne asbestos fibres. 


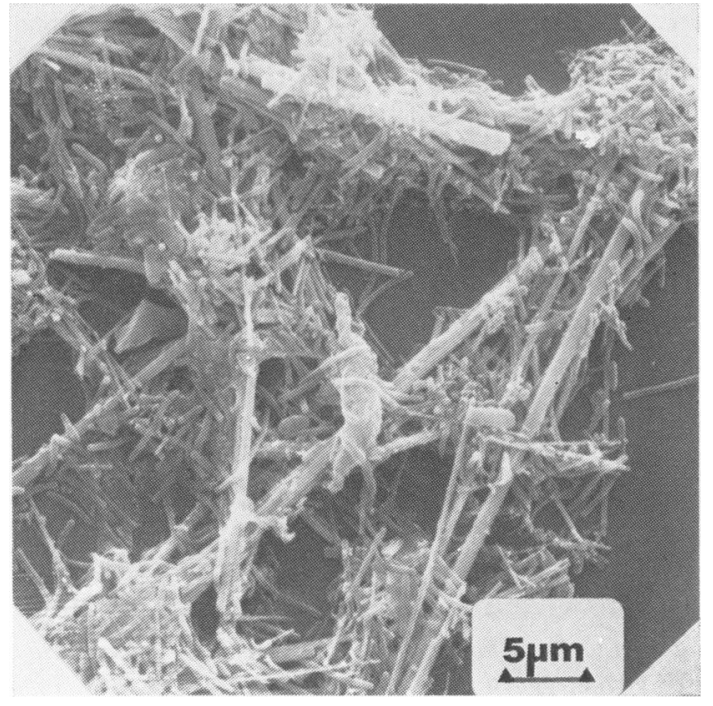

Fig 7 A lump of micro-organisms and crocidolite fibres photographed at $\times 2000$ in secondary electron mode.

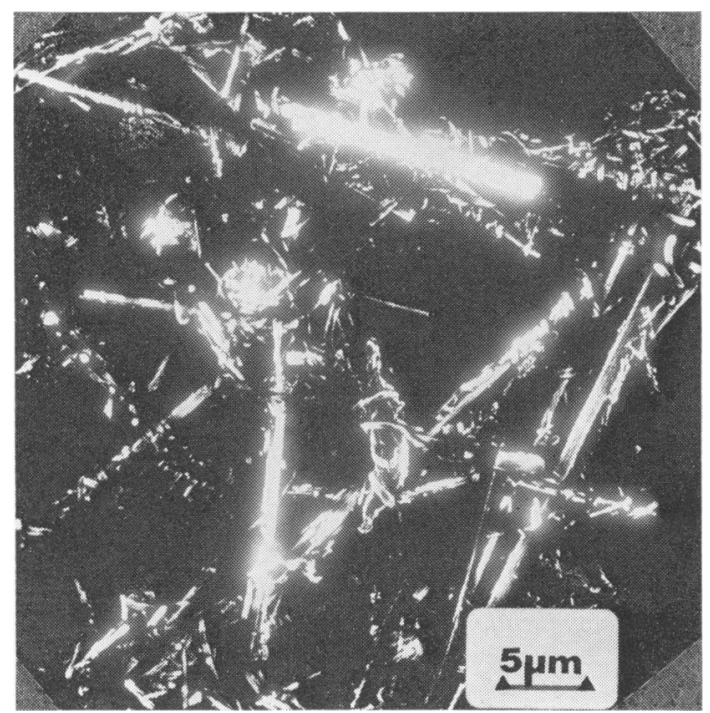

Fig 8 A lump of micro-organisms and crocidolite fibres photographed at $\times 2000$ in backscattered electron mode indicating location of fibres.

We show here that the recovery of fibres after wet-digestion/extraction procedures is of the order of $30-40 \%$ by number. No attempt has been made to investigate the effect of the fibre loss on the fibre size distribution, however; short and thin fibres as well as large asbestos bodies were detected on the glass. As the main loss is due to particle adhesion to the beaker, the period the fibres are kept in solution must be reduced to a minimum. The adhesion is probably not related to particle size, and it may be avoided to some degree by continuous agitation of the suspensions. This effect should be carefully considered during analyses of fibres in, for example, urine and water samples.

The advantage of low-temperature plasma ashing is that the residue may be dispersed and immediately filtered with a minimum fibre loss. The disadvantage, however, is that only dried tissue can be ashed, introducing errors due to fibres breaking during shrinkage. Gylseth et $a l^{6}$ have shown that this effect induces an increase of about $35 \%$ in the number of fibres when comparing low-temperature ashed samples to directly filtered wet-digested samples. The average ratio between the fibre numbers obtained by direct filtration of standard UICC crocidolite and by the wet-digestion procedure is 3.0 . The ratio obtained between low-temperature ashing and wet-digestion is $\mathbf{4 . 3}$ for the first set of samples and 4.0 for the second. Given that fibres extracted from tissue samples are increased by 30 $40 \%$ due to shrinkage, the ratios between the different methods are about 3 , both based on analysis of standard UICC crocidolite as well as lung tissue samples from exposed individuals.

Wet-digestion is a rather time-consuming technique that gives significant fibre loss due to the particle adhesion and fibres discarded in the supernatant. The adhesion to the glass has been observed for other particulates, such as quartz and calcium silicates ( $\mathrm{H}$ Gylseth et al, unpublished data), and thus probably has little to do with the morphology or chemistry of the particles.

Though we have shown that micro-organisms grow fast together with particulates in distilled water and attach strongly to the walls, this cannot be the cause as long as adherence occurs in $4 \%$ formaldehyde solution as well. The adhesion may be due to other causes, perhaps to physical forces. We tried to reduce the surface charge by adding a surface active substance (hyamine), but no significant effect was observed. Ashcroft and Heppleston ${ }^{2}$ who have observed the adhesion thought that it was caused by a sticky film derived from the organic material in the digested lung, but since the adhesion occurs even in distilled water containing standard fibres there must be another cause. The fibres attach to the glass after a rather short time and seem to be strongly adherent, ultrasonication failing to release them. Even large particles, such as asbestos bodies, are still adhered after sonication. No mechanical reason for the adhesion has been observed in the scanning electron micrographs.

The best way to avoid significant particle loss 
during sample preparation for fibre quantification, is to reduce the period needed for preparation as well as the number of times the suspensions are transferred between vials. Laboratory equipment that has been used for storing fibre solutions should be thoroughly cleaned before it is used for the next analysis, otherwise contamination might occur.

We thank the departments of pathology at the Norwegian State Hospital and Aker Hospital for supplying us with lung tissue samples.

\section{References}

${ }^{1}$ Pooley FD, Clark NJ. A comparison of fibre dimensions in chrysotile, crocidolite and amosite particles from samples of airborne dust and from post-mortem lung tissue specimens. In: Wagner $\mathrm{JC}$, ed. The biological effects of mineral fibres. Vol I. Lyon: IARC, 1980: 79-86. (Publ No 30.)

${ }^{2}$ Ashcroft T, Heppleston AG. The optical and electron microscopic determination of pulmonary asbestos fibre concentration and its relation to the human pathological reaction. $J$ Clin Pathol 1973;26:224-34.

${ }^{3}$ Sebastien P, Fondimare A, Bignon J, Monchaux G,
Desbordes J, Bonnaud G. Topographic distribution of asbestos fibres in human lungs in relation to occupational and non-occupational exposure. In: Walton $\mathrm{WH}$, ed. Inhaled particles IV. Vol 2. Oxford: Pergamon Press, 1977:435-44.

${ }^{4}$ Morgan A, Holmes A. Concentrations and dimensions of coated and uncoated asbestos fibres in the human lung. Br J Ind Med 1980;37:25-32.

${ }^{5}$ Friedrichs $\mathrm{KH}$, Otto $\mathrm{H}$. Fibers in human lung dust samples: a scanning electron microscope study. $\mathrm{Am}$ Ind Hyg Assoc $J$ 1981;42:150-6.

${ }^{6}$ Gylseth B, Baunan RH, Bruun R. Analysis of inorganic fibers in biological samples by scanning electron microscopy. Scand J Work Environ Health 1981;7:101-8.

${ }^{7}$ Bouffant L. Investigation and analysis of asbestos fibres and accompanying minerals in biological materials. Environ Health Perspect 1974;9:149-54.

${ }^{8}$ Stolkin I, Rüttner JR, Sahu AP, Schibli L, Spycher MA. Elektronenmikroskopische Bestimmung von Zahl und Grøssenverteilung von mineralischen Fasern in asbestexponierten und nicht asbestexponierten Lungen. Staub Reinhaltung der Luft 1981;41:188-222.

${ }^{9}$ Gylseth B, Baunan RH. Topographic and size distribution of asbestos bodies in exposed human lungs. Scand $J$ Work Environ Health 1981;7:190-5.

${ }^{10}$ Weill H. In: Wagner JC, ed. The biological effects of mineral fibres. Vol II. Lyon: IARC, 1980:867-73. (Publ No 30.) 